\title{
A CENA FILOSÓFICA, ESTUDO SOBRE O MÉTODO DE LEITURA DE FREDERIC COSSUTTA
}

\begin{abstract}
André Luis La Salvia*
Resumo: $\mathrm{O}$ artigo analisa a metodologia de leitura de textos filosóficos proposta por Frederic Cossutta. Este artigo faz parte de um projeto de pesquisa que tem por finalidade delimitar um arcabouço teórico que permita a formalização de conteúdos didáticos para aplicação em sala de aula no ensino de filosofia. Neste momento, dedicamos atenção à noção de 'cena filosófica' criada por Cossutta, procuramos analisar suas características e como nela estão fundados os elementos para leitura de textos filosóficos.
\end{abstract}

Palavras-chave: filosofia, método, leitura, Cossutta, ensino

Resumen: El trabajo analisa la metodología de la lectura de textos filosóficos propuestos por Frederico Cossutta. Este artículo es parte de um proyecto de investigación que tiene como objetivo definir un marco que permite la formalización de los contenidos educativos para su uso en el aula de enseñanza de la filosofia. Ahora mismo, estamos prestando atención a la noción de 'escena filosófica' creado por Cossutta, analizamos sus características y como los elementos enque se basan para la lectura de textos filosóficos.

Palabras clave: filosofía, método, lectura, Cossutta, enseñanza

\section{Introdução}

A teoria apropriada será aquela que se ajustará melhor a natureza do objeto, sem reduzir sua complexidade ${ }^{1}$ (COSSUTTA, 1995).

Através do livro Elementos para a leitura de textos filosóficos, Frederic Cossutta (1994) não esboçará um método de interpretação das diversas filosofias ou da História da filosofia. Mas, como ressalta o título da obra, tentará estabelecer uma ferramentaria mínima (os elementos) que permitirão ao leitor enfrentar cada texto filosófico como um complexo produtor de sentidos.

\footnotetext{
"Doutorando em Filosofia. Unicamp. E-mail: salviala@gmail.com

1 As traduções dos artigos originalmente em francês são do autor especialmente para esse artigo.
}

LA SALVIA, André Luis. A cena filosófica, estudo sobre o método de leitura de Frederic Cossutta. Revista Sul-Americana de Filosofia e Educação. Número 19: nov/2012abr/2013, p. 74-88. 
Nosso objetivo foi pesquisar e analisar a problemática de se encarar a filosofia como um discurso dotado de características especiais que a torna uma produtora de sentidos. Desse modo, analisamos a exposição de Cossutta dos elementos que dão acesso aos sentidos das teorias filosóficas.

Neste artigo, gostaríamos de destacar a noção de 'Cena Filosófica' como o principal conceito desse método de leitura de textos filosóficos. De modo que pretendemos analisar como Frederic Cossutta constrói esse conceito e como seria possível adaptá-lo para uma propedêutica da filosofia na montagem de aulas para alunos do ensino médio².

Há de se ressaltar que este método tem uma perspectiva de análise de discurso, mas que, em nenhum momento, negligencia a capacidade interpretativa do exegeta do texto filosófico porque, por mais que entenda que há procedimentos comuns que justificam a existência do manual, eles existem para preparar a experimentação do leitor: "esse manual é destinado a facilitar essa pesquisa, oferecendo elementos que não pretendem substituir o trabalho de interpretação, mas que permite prepará-lo" (COSSUTTA, 1994, p. 7).

\section{A filosofia como produtora de sentido}

$\mathrm{Na}$ construção de seus elementos, Cossutta tenta fugir de três grandes objeções feitas a toda tentativa de método: cair no impasse do bom senso que confunde método com explicação do texto; cair na formulação de um método 'ideal' que se torna até mais importante que a própria filosofia estudada; ou ainda, cair em um ceticismo que diria que cada filosofia coloca as bases de sua própria interpretação impossibilitando um método geral.

Paradoxalmente, é neste último ponto que se ancora o trabalho de Cossutta. É exatamente o fato de cada filosofia criar as condições de sua própria existência que faz dela um tipo de discurso especial, um discurso constituinte. Ou seja, para Cossutta, "todas as obras constroem uma teoria geral do conhecimento, do sentido e da linguagem" (COSSUTTA, 1994, p. 3), o que lhe permite deduzir

\footnotetext{
${ }^{2}$ Período da Educação Básica no Brasil que compreende os alunos entre 15 a 17 anos.
} 
que o método deve ser uma "teoria da produção do sentido" (COSSUTTA, 1994, p. 4). Essa característica, longe de impossibilitar um método, o funda. Por isso, precisamos analisar quais são as características dos discursos constituintes.

Em artigos posteriores ao livro que estamos analisando, Cossutta ressaltou as características do discurso filosófico como um discurso constituinte. Discursos constituintes $^{3}$ são todos aqueles em que "a pretensão ligada ao estatuto de discurso constituinte é fundar e não ser fundado" (MAINGUENEAU, 1995, p. 112). O que significa dizer que:

Uma das tarefas prioritárias de toda filosofia, seja ela antisistemática ou 'anti-filosófica', consiste, com efeito, em explicitar seu próprio modo de constituição, isto é, em lançar mão apenas de sua própria autoridade para estabelecer as condições de validade dos seus próprios enunciados, assim como as condições de validação de todo enunciado (COSSUTTA, 1995, p. 12-13).

As teorias filosóficas, como discursos constituintes produtores de sentidos, devem criar e explicitar as condições de sua possibilidade, legitimar essas condições e validar a sua existência. Para nosso acesso ao pensamento de Cossutta, aproximamos aqui as características atribuídas a filosofia em diferentes obras do autor, a saber, a produção de sentidos (presente na obra Elementos) com a pretensão de fundar os discursos, enquanto um arché dos discursos (artigos sobre o discurso constituinte). Fruto dessa aproximação, podemos dizer que as filosofias enquanto produtoras de sentidos fazem seu movimento de constituição ao mesmo tempo que tornam inteligíveis as condições de sua própria inteligibilidade e de sua própria experimentação.

Com esse ancoradouro, o método de Cossutta permite saiar do impasse que surge ao dizer que cada filosofia cria as bases de sua própria interpretação (autonomia que impossibilitaria um método geral de leitura). Para sair desse impasse, Cossutta precisa descrever as condições para o discurso filosófico se lançar como um discurso constituinte produtor de sentidos, ou seja, descreve

3 Outros tipos de discursos constituintes são o cientifico, religioso, literário e jurídico. 
algumas características gerais de todo discurso filosófico para afirmar como ele instaura as condições de sua própria existência e legitimidade:

a) todo texto filosófico tenta mediatizar a relação do particular ao universal;

b) o que torna as filosofias contraditórias (cada uma constrói seu sentido) é o que as aproxima (todas constroem sentidos);

c) toda filosofia deve, implícita ou explicitamente, validar sua possibilidade enunciativa;

d) toda filosofia deve efetuar escolhas em face da tripla exigência que comanda sua ordenação: ordem da descoberta, ordem lógica (ordem das razões) e ordem de exposição (COSSUTTA, 1994, p. 5).

Novamente ao confrontar as características do discurso filosófico acima citadas, presentes no livo Elementos, com o artigo de Cossutta e Maingueneau (1995), temos a noção de que o discurso filosófico é aquele que, ao mesmo tempo que explicita as condições de sua própria possibilidade, inscreve as formas conceituais e lógicas nas formas expressivas ${ }^{4}$. Ora o discurso filosófico faz isso ao mediatizar a relação entre o caso particular analisado e a universalidade conceitual, ao validar suas próprias condições de existência e, por fim, ao agenciar expressivamente a ordem de descoberta, a lógica interna e a exposição de seus conceitos. E o mecanismo pelo qual cada teoria filosófica agencia todos esses elementos é a criação de uma 'cena filosófica', como "resultado desse trabalho de escrita pelo qual o filósofo representa o processo de pensamento no âmago do próprio texto" (COSSUTTA, 1994, p. 14). Por isso, este conceito de 'cena filosófica' e tão importante e é o objetivo de nosso estudo, porque é nele que os conceitos filosóficos vibram entre os traços ontológicos de sua constituição com a didática pedagógica de sua inteligibilidade.

\section{A 'Cena Filosófica'}

4 "O projeto começou por articular as operações discursivas a seus substratos linguisticos, por apreender na sua especificidade um tipo de discurso que visa a explicitação maxima de suas próprias condições de possibilidade. Também colocou em evidencia as relações intimas que na filosofia inscrevem as formas conceituais e lógicas nas formas expressivas" .Maingueneau Dominique, Cossutta Frédéric. L'analyse des discours constituants. In: Langages, 29e année, n¹17, 1995. pp.112-125. P114. 
Para Cossutta, deve-se ler e reler uma teoria filosófica para conseguir captar as referências internas que "efetuam seu sentido e lhe conferem sua unidade" (COSSUTTA, 1994, p. 7). Ler é percorrer essas referências internas em "um constante movimento de vaivém que liga e sobrepõe simultaneamente os constituintes da frase e as frases entre si" (COSSUTTA, 1994, p. 7) onde o leitor desloca-se do agenciamento linear fixo da escrita para uma simultaneidade virtual, limitada somente pela sua própria capacidade de memorização. Por isso, "a posição da cena filosófica determina, portanto, um pólo de unificação textual, assegura por sua presença constante um suporte ao desenvolver uma reflexão" (COSSUTTA, 1994, p. 34), tornando-se uma unidade de sentido global de uma filosofia.

Portanto, os elementos para a leitura de textos filosóficos são os componentes integrantes a 'cena filosófica', porque são responsáveis por uma coesão interna capaz de conferir sentido a uma teoria e são o suporte para o desenvolvimento da trama da criação desse sentido. Esse é o primeiro passo do método: entender o conceito de 'cena filosófica' como aquele que tenta dar conta de pensar a estrutura de enunciação filosófica, entendendo-a como uma dramatização. $\mathrm{Na}$ dramatização, as pessoas do discurso são colocadas em diferentes relações a partir de um sujeito enunciador e de um conceito enunciado. Por isso separamos os elementos do conceito de 'cena filosófica' em dois grupos a serem analisados a partir de agora: os sujeitos dos enunciados que dramatizam a cena; e o grupo formado pelos conceitos, os operadores semânticos da cena.

O sujeito enunciador agencia as pessoas do discurso: o próprio sujeito enunciador que se coloca; o leitor, colocado como função de endereçamento (segunda pessoa); as outras teorias filosóficas (terceiras pessoas), algumas agenciadas como aliadas outras como opositoras. Desse modo, "o dispositivo enunciativo das pessoas atesta uma presença, cria um estilo e divide a palavra e os papéis segundo regras" (COSSUTTA, 1994, p. 211).

A conceitualização por sua vez, tem a função de mediadora na organização da ordem interna do discurso agenciando como componentes: as teses enunciadas, as argumentações, os processos de validação das teses com 
justificativas, com sua capacidade persuasiva e com sua própria legitimação; e as metáforas e exemplos como componentes das conceitualizações, pois ligam os conceitos ao mundo.

\section{As pessoas na 'cena filosófica'}

As pessoas do discurso são responsáveis pela dramatização da cena filosófica ao desempenhar papéis agenciados pelo autor. De modo resumido, podemos encontrar na longa citação abaixo as pessoas integrantes da 'cena filosófica' com a sua função principal:

...enfim, sobre essas posições edificam-se as funções fundamentais da discursividade filosófica: sobre a primeira, tudo o que diz respeito às relações entre a verdade e sua efetuação na linguagem e na ordem do discurso; sobre a segunda, as funções didáticas $e$ pedagógicas que estabelecem as condições de inteligibilidade do texto e o caminho que conduz ao domínio doutrinal; sobre a terceira, a dimensão polêmica e dialógica que constrói um volume intertextual em constante elaboração (COSSUTTA, 1994, p. 35).

Se o primeiro passo do método era entender o texto filosófico como um complexo produtor de sentidos, captar as funcionalidades das pessoas parece ser o seu segundo passo. Desse modo, a primeira pessoa se coloca como regente da distribuição dos papéis e pessoas na dramatização de produção conceitual de uma teoria e por isso "o leitor deve buscar as marcas explícitas da enunciação filosófica, referindo os enunciados em três pólos" (COSSUTTA, 1994, p. 11):

- primeira pessoa - sujeito enunciador - o nome próprio, ou pronome em primeira pessoa, ou denominações de escola; é o responsável pelo discurso; aquele que "agencia do interior a função autor" - Ex.: "Na primeira, adianto as razão pelas quais podemos geralmente duvidar de tudo" (Descartes, citado por COSSUTTA, 1994, p. 19);

- segunda pessoa - função de endereçamento - como se constrói o receptor do texto para tentar persuadi-lo ou levá-lo a filosofar - Ex.: "Apegue-se, 
pois, aos ensinamentos que não cessei de lhe dar e que vou repetir; ponhaos em prática e medite-os, convencido de que neles residem os princípios necessários para bem viver. Comece por persuadir-se de que..." (Epicuro, citado por COSSUTTA, 1994, p. 26);

- terceira pessoa - o outro - os outros autores, correntes de ideias, escolas (citadas ou apenas aludidas) com as quais concorda ou discorda - Ex.: "Uma convicção dogmática é uma opinião que se crê estabelecida por um raciocínio, por uma analogia ou por alguma demonstração... Nós os opomos mutuamente de início, reciprocamente em seguida..." (Dumont, citado por COSSUTTA, 1994, p. 32).

Toda filosofia possui sua 'cena filosófica' para produzir o seu sentido. E, além de diferentes conceitos enunciados, existem diferentes estilos de agenciar os três pólos acima citados.

O sujeito enunciador, autor da elaboração discursiva é a origem do enunciado, pode variar em quatro estilos: o primeiro é o enunciador universal (aquele que apaga as marcas pessoais, uma forma vazia que engloba a segunda $e$ terceira pessoa, como se fosse "ponto de pura transparência em que a verdade se manifesta" (COSSUTTA, 1994, p. 15). Ex.: "O tempo infinito, contém a mesma fonte de prazer que o tempo finito contanto que seus limites sejam medidos pela razão" (Epicuro, citado por COSSUTTA, 1994, p. 15);

O segundo estilo seria o enunciador de referência que assegura a funçãoautor. Há o índice linguístico de primeira pessoa, mas apagado em nome da universalidade. Ex.: "Indicamos na Ética (...) mas o objetivo de nossa discussão presente é mostrar que (...); assim, como dissemos acima..." (Aristóteles, citado por COSSUTTA, p. 17).

O terceiro estilo, Cossutta chama de identificação participadora, quando o índice linguístico 'eu' pode ser identificado a uma teoria especifica (como o eu cartesiano, o eu sartriano). Ex.: "Esta proposição: sou, existo, é necessariamente verdadeira todas as vezes que a pronuncio ou que a concebo em meu espírito" (Descartes, citado por COSSUTTA, 1994, p. 19). 
Por fim, o quarto estilo do componente primeira pessoa do conceito de 'cena filosófica' é o enunciador singularizado, quando traços biográficos fazem parte da trama. Ex.: "Prevendo que me caberá em breve lançar à humanidade o mais grave desafio que ela já recebeu, parece-me indispensável dizer quem sou" (Nietzsche citado por COSSUTTA, 1994, p. 21).

Não é o objetivo da presente análise detalhar a operacionalidade desse componente, porém, ressaltamos que Cossutta dedicou um artigo à análise do ponto de vista da função-autor ${ }^{5}$.

Com relação ao componente função de endereçamento do conceito de 'cena filosófica', teremos uma nova rede de variações de estilos proporcionais aos estilos do sujeito enunciador. Desse modo, o primeiro estilo seria o destinatário universal (endereçado a todos). O segundo estilo é o destinatário incluso (nós, a gente, inclui o leitor). O terceiro o destinatário de exclusão (vocês, vós). E o quarto, a proximidade (tu, amigos, o leitor-irmão).

A segunda pessoa desempenha o papel fundamental, pois serve como mediador do autor com ele mesmo e também como mediador entre a fonte do enunciado e a comunidade mais ampla, o campo social e institucional, que a teoria se inscreve ou pode atingir. Além de mediadora, a segunda pessoa aprende, pois não é puramente passiva, opõe a resistência de sua incompreensão, preconceitos e objeções. Existem inclusive gêneros discursivos sob o primado da segunda pessoa: as correspondências e cartas filosóficas (como o exemplo de Epicuro citado acima), o diálogo (Platão, notoriamente).

Ainda com relação a função de endereçamento, os textos em que a segunda pessoa desempenham ou uma função pedagógica quando faz explicitamente o esforço de conversão do leitor, ex: "Com efeito, isso também faz parte de minha felicidade: esforçar-me para que muitos outros compreendam o que compreendo a fim de que o seu entendimento e seus desejos entrem em perfeito acordo com o meu entendimento e o meu desejo", (Espinosa, citado por COSSUTTA, 1994, p. 29); ou uma função didática quando faz a explicitação das

5 Referimo-nos ao artigo "Neutralisation du point de vue et stratégies argumentatives dans le discours philosophique ».Semen [En ligne], 17 | 2004, mis en ligne le 29 avril 2007. 
condições de inteligibilidade do próprio texto, ex.: "(...)para evitar as delongas de uma teoria completa e no entanto nada negligenciar numa pesquisa completa, achei mais conveniente preparar o leitor do que instruí-lo pelos quatro números que se seguem, e só apresentar sistematicamente a explicação desses elementos do entendimento na terceira seção que vem imediatamente após" (Kant, citado por COSSUTTA, 1994, p. 28).

Já na terceira pessoa, a variação se dá nas diferentes teorias filosóficas pré-existentes que vão sendo arregimentadas ao longo da exposição, algumas como filiações, aliadas, amizades outras como refutações, opositoras e críticas. A terceira pessoa tem uma função dialógica ou polêmica já que "cada filosofia deve, portanto, resolver de maneira determinada o problema de sua inserção no campo pré-constituído dos saberes, das práticas e das filosofias já instalados" (COSSUTTA, 1994, p. 30), ex.: "A maior parte das proposições e das questões que foram escritas sobre matérias filosóficas não são exatamente falsas, mas desprovidas de sentido. Por essa razão não podemos absolutamente responder às questões desse gênero, mas apenas estabelecer que elas são desprovidas de sentido" Wittgenstein, citado por (COSSUTTA, 1994, p. 33).

\section{Os conceitos}

Os conceitos, ao mesmo tempo, posicionam as pessoas acima citadas $e$ são os intermediários entre o abstrato e o vívido, entre o particular e o universal. É em torno de um conceito que as pessoas do discurso são agenciadas, ao mesmo tempo, é ele também, na sua semântica conceitual, que "permite categorizar o real ou o ser integrando-os no domínio do dizível" (COSSUTTA, 1994, p. 40). Por isso foi dito acima que o conceito desempenha uma função mediadora, organizador da ordem interna do discurso, pois é ele também que opera a mediação entre o particular e o universal, ao mesmo tempo que explicita as condições de sua própria possibilidade dentro de uma ordem interna que agencia a ordem da descoberta, das razões e da exposição na construção do sentido. 
Ao estabelecer a função conceitual cada teoria reforça ainda mais a característica de discurso constituinte, uma vez que o conceito estabelece a relação necessária entre a constituição do conteúdo da teoria, bem como a constituição da reflexão sobre o próprio modo de constituição da teoria, sua auto-constituição: "uma das características fundamentais dos discursos constituintes é a autoconstituição que permite sempre a uma doutrina refletir seus modos de elaboração ou de exposição nas suas próprias categorias doutrinais." (COSSUTTA, 2004, p. 11). Cossuta afirma que "a filosofia se caracteriza pela auto-explicação de suas categorias semânticas" e, ao mesmo tempo, "ela própria está, enquanto objeto do mundo, sujeita ao esquema conceitual que organiza" (COSSUTTA, 1994, p. 68).

Após o primeiro passo do método que é a percepção de que o texto filosófico é um complexo produtor de sentidos através da colocação de uma 'cena filosófica', e depois do segundo passo que é a análise das pessoas do discurso em suas funcionalidades, chegamos ao terceiro passo do método, a saber, analisar a construção conceitual e "por quais procedimentos unidades de sentido são fixadas, ligadas, hierarquizadas para constituir um universo autônomo de significação" (COSSUTTA, 1994, p. 52).

A função conceitual possui um núcleo definicional onde o filósofo explicita as significações das expressões que usa. O procedimento de análise da função conceitual desse núcleo definicional é dividida em três partes: o termo significante (escolha de um termo, fixação do seu significante); o sentido (traços definicionais, elementos diferenciadores que estabelecem relações); e a referência (elementos extralinguísticos manifestados através dos exemplos e dos casos particulares). Como explicitado na citação abaixo:

Para isso ele deve articular um termo significante (aquele que figura no léxico de uma doutrina ou da filosofia em geral) a um sentido (conjunto de propriedades que o especificam) e uma referência (designação de entidades extralinguísticas) (COSSUTTA, 1994, p. 50).

Desse modo, o trabalho do filósofo é "fixar sentido, referência, produzir relações e fornecer as regras que permitam sua reutilização" (COSSUTTA, 1994, p. 
53). E o trabalho do leitor é analisar as operações pelas quais o filósofo explicita a relação entre o termo significante, o sentido e a referência. O exemplo abaixo é bastante elucidativo:

Todas as percepções do espírito humano se reduzem a dois gêneros distintos que chamarei impressôes e ideias. A sua diferença reside nos graus de força e vivacidade, com os quais elas golpeiam a inteligência $e$ abrem o seu caminho no nosso pensamento e consciência. As percepções que penetram com maior força e violência, podemos nomeá-las impressões; e sob essa denominação compreendo todas as nossas sensações, paixões e emoções, tais como elas fazem sua primeira aparição na alma. Por ideias, entendo as imagens apagadas das impressões em nossos pensamentos e nossos raciocínios; tais são por exemplo, todas as percepções espertadas pela presente exposição... (Hume, citado por COSSUTTA, 1994, p. 43)

No exemplo, como conceitualização, temos os termos impressóes e ideias, com as explicitações dos seus significados e também com a colocação de referências. O trabalho de análise passa portanto pela apreensão dos processos de criação conceitual: a apreensão do núcleo definicional de conceitos, mas também será seguido pelos processos argumentativos que legitimam e dão sentido ao conceito, estabelecendo um processo de validação; e o estabelecimento de metáforas e exemplos que unem os conceitos e argumentações a um mundo denotativo.

O processo de validação é o mecanismo pelo qual o filósofo argumenta ou demonstra a fim de legitimar, justificar e persuadir o leitor. Através desse processo que a auto-consistência de uma teoria se forma já que

Com a argumentação tocamos em uma função filosófica essencial: de fato, ela não procede apenas à construção e à legitimação das teses, embora seja esse seu papel mais visível e certamente o mais fundamental, mas permite também construir e legitimar os outros elementos constituintes da doutrina (problematizações, escolhas temáticas, refutações e incorporação das teorias adversas, construções conceituais...) ela desempenha também um papel importante na repartição de subconjuntos que compõem a totalidade sistemática, já que ordem de exposição deve também ser pensada (COSSUTTA, 1994, p. 196). 
Os filósofos não escolhem seus conceitos aleatoriamente, muito pelo contrário, faz parte do discurso constituinte justificar e legitimar as escolhas das palavras, como se cada teoria reinventasse a linguagem. E cada teoria agencia os componentes conceituais a sua maneira, dentro de seus interesses. Se voltarmos a recorrer a continuidade do exemplo dado acima do texto de David Hume, vamos conferir essas características descritas, onde o autor procura legitimar suas escolhas conceituais com argumentos, exemplos e contraposição a uma outra teoria:

Cada um por si mesmo perceberá facilmente a diferença entre sentir e pensar. Os graus usuais de um e de outro se distinguem sem dificuldade: no entanto não é impossível que, em casos particulares, eles possam se aproximar muito um do outro. Assim, no sono, na febre, na loucura ou em toda emoção muito violenta da alma, nossas ideias podem se aproximar de nossas impressões, assim como acontece as vezes, por outro lado, que nossas impressões estão tão fracas que não podemos distingui-las de nossas ideias. Mas, a despeito dessa grande semelhança num pequeno número de casos, elas são em geral, muito diferentes, a tal ponto que ninguém pode hesitar em ordená-las sob títulos diferentes, nem em atribuir a cada uma um nome particular para marcar sua diferença. Emprego aqui as palavras impressão e ideia num sentido diferente do habitual, esperando que me concedam essa liberdade. Talvez eu esteja sobretudo restabelecendo o sentido primitivo da palavra ideia, sentido que o sr. Locke havia alterado para fazê-la designar todas as nossas percepções (Hume, citado por COSSUTTA, 1994, p. 43).

Analisando o exemplo de Hume, observamos que o sujeito enunciador varia do enunciador de referencia para a identificação participadora quando marca sua diferença com Hume. O sujeito coloca os conceitos de impressões e ideias com seus significados e referências. Hume ainda demonstra a validade de seus conceitos justificando suas escolhas e divergindo de Locke.

Além do processo de validação, os filósofos lançam mão de metáforas e exemplos que ligam o processo de criação conceitual ao mundo, pois "é efetivamente de nosso mundo que os textos filosóficos tratam, e é para torná-lo inteligível que os filósofos o transpõem para o discurso através de um universo denotativo ideal" (COSSUTTA, 1994, p95).

No caso dos exemplos, Cossutta lança mão dos componentes dessa denotação espaço-temporal separando um universo denotativo ideal de um 
substrato ontológico, sendo o primeiro os objetos do pensamento na construção do conceito e o segundo as referências aos objetos do mundo, os casos particulares, os exemplos, as passagens descritivas, o 'real' do campo perceptivo. No nosso exemplo, quando Hume faz referência ao sono, febre e loucura para construir sua demonstração.

Já a metáfora conecta uma imagem ou uma referencia concreta à uma abstração, nas palavras de Cossutta "as metáforas interrompem a exposição abstrata ou nela insinuam-se para substitui-la por um outro plano de significação caracterizado pelo emprego de imagens, cuja função parece ser a de oferecer um equivalente concreto da análise" (COSSUTTA, 1994, p102). Uma das mais gastas metáforas da história da filosofia é a analogia entre a 'trazer a luz', a 'clarificação' com o 'entender', o 'entendimento'. Cossutta afirma que as alegorias, mitos e fábulas são processos metafóricos da expressividade filosófica.

Se formos, portanto, resumir o que foi dito, os elementos para a leitura de textos filosóficos de Cossutta levam em conta que cada teoria filosófica é um discurso constituinte produtor de sentido operando através do estabelecimento de uma 'cena filosófica' onde as pessoas do discurso são agenciadas pela função autor na criação do conceito como eminentemente filosófico. O conceito configura-se como mediador das pessoas na cena e legitima e constitui o discurso filosófico. Para constituir o discurso filosófico, cada conceito construído possui seu próprio processo de validação, através do qual instaura argumentações e demonstrações que legitimam, justificam e persuadem o leitor sobre a sua teoria, além de lançar mão de metáforas e exemplos que conectam a teoria a um mundo denotativo.

\section{Conclusão: uma pedagogia possível}

O objetivo desse artigo, ao analisar o método de leitura de Frederic Cossutta, é pesquisar um procedimento que fundamente a elaboração de uma didática aplicada ao ensino de filosofia no nível médio. Acreditamos que a obra de Cossutta, e em particular a noção de 'cena filosófica' é um excelente incentivo para esse trabalho ao nos propor encarar a operacionalidade própria da filosofia como 
discurso constituinte produtor de sentido. Ao mesmo tempo, essa operacionalidade é suficientemente cuidadosa para fazer com que "os grandes pensadores" apareçam como sendo "aqueles que fazem de seu pensamento um estilo" (COSSUTTA, 1994, p 236). Por isso, utilizamos agora a expressão "pedagogia do conceito" para designar a modalidade de ensino de filosofia que encara o conceito como peça fundamental do discurso filosófico. Fundamental porque as teorias filosóficas são criadoras de conceitos e também porque essa expressão designa a pedagogicidade de um tipo de discurso que precisa justificar, explicitar, legitimar as condições de sua própria existência:

Cada doutrina produz seu próprio universo de discurso, e lhe é necessário manter a exigência de um retorno ao mundo da experiência comum. Ela se vê, assim, obrigada a ligar estreitamente pedagogia e ontologia (COSSUTTA, 1994, p. 61).

Mesmo que tenham ideias distintas da instância pedagógica e da instância ontológica e dos seus cruzamentos

Toda a filosofia é atravessada por uma tensão entre duas exigências complementares. Com efeito, se a filosofia, de maneira as vezes vertiginosa, cria um universo denotativo, trata-se sempre de um universo ideal que, diferentemente daquele engendrado pelo artista, não oferece um substituto estético do visível, mas propõe um esquema de inteligibilidade dele e encontra nisso a sua legitimidade (COSSUTTA, 1994, p. 61).

É exatamente o fato de que a filosofia é um discurso constituinte produtor de sentido que faz com que o conceito (este seu produto original) seja o organizador da ordem interna do discurso, ordem ao longo da qual ele mesmo precisa criar as condições de sua inteligibilidade. Assim procedendo, ele promove seu didatismo como característica imanente do seu próprio dinamismo. No movimento de sua criação, o conceito precisa tornar inteligíveis as condições de seu entendimento e interpretação. Por isso, na dinâmica da criação conceitual é que podemos encontrar as condições de construção de uma didática aplicada da filosofia: o conceito vibra entre os traços ontológicos de sua criação filosófica e a didática pedagógica de sua própria inteligibilidade. 
Salientamos a necessidade de uma análise precisa da 'cena filosófica' na perspectiva de uma "pedagogia do conceito", pedagogia que se envolve com questões suscitadas pela busca do sentido de uma teoria filosófica, busca justamente ordenada pela análise da construção conceitual desse sentido. Acabamos de fazer apenas uma apresentação inicial da 'cena filosófica' concebida por Cossutta. Nós a apreendemos como método de leitura, método que faz ao professor $e$ ao estudante um apelo à livre experimentação em seus encontros com textos filosóficos: que cada um, tocado pelos conceitos, sinta os efeitos da cena em sua própria potência de pensar.

\section{Referências}

COSSUTTA, Frederic. Elementos para a leitura dos textos filosóficos. São Paulo: Martins Fontes, 1994.

COSSUTTA Frédéric. Pour une analyse du discours philosophique. In: Langages, $29 e$ année, n¹19, 1995. pp. 12-39. doi : 10.3406/lgge.1995.1721 http://www.persee.fr/web/revues/home/prescript/article/lgge 0458726X_1995_num_29_119_1721.

COSSUTTA, Frédéric "Neutralisation du point de vue et stratégies argumentatives dans le discours philosophique », Semen [En ligne], 17 | 2004, mis en ligne le 29 avril 2007. URL: http://semen.revues.org/2321.

MAINGUENEAU, Dominique, Cossutta Frédéric. L'analyse des discours constituants. In: Langages, 29e année, n¹17, 1995. pp.112-125. Doi : 10.3406/lgge.1995.1709 http://www.persee.fr/web/revues/home/prescript/article/lgge 0458726X 1995 num 291171709.

MAINGUENEAU, Dominique. L'énonciation philosophique comme institution discursive. In: Langages, 29e année, n¹19, 1995. pp. 40-62.doi : 10.3406/lgge.1995.1722 http://www.persee.fr/web/revues/home/prescript/article/lgge 0458726X_1995_num_29_119_1722.

ROLIM, Wiliane Viriato. A filosofia como discurso constituinte. Letras \& Letras, Uberlândia 22 (2) 47-54, jul./dez. 2006 